\title{
INVESTIGATION OF WHETHER UNDERGRADUATES CAN TAKE COLLECTIVE COGNITIVE RESPONSIBILITY IN THE KNOWLEDGE BUILDING PROCESS
}

\author{
Qianqian Chen, Yuqin Yang and Chen Xu \\ Central China Normal University \\ Central China Normal University, NO.152 Luoyu Road, Wuhan, Hubei, P. R. China, 430079
}

\begin{abstract}
This study investigates whether undergraduates were able to take collective responsibility to gradually improve community knowledge. The participants were 30 undergraduates from 24 majors in a key normal university. The analysis of their online Knowledge Forum writing indicated that the undergraduates were aware of peers' contributions, made complementary contributions, and showed distributed engagement, and thus they could take collective cognitive responsibility. The results also showed that students gradually improved community ideas. This study has implications for teachers who aim to design technology-enhanced learning environments to engage students.
\end{abstract}

\section{KEYWORDS}

Collective Cognitive Responsibility, Knowledge Building, Engagement

\section{INTRODUCTION}

Collaborative inquiry, a major research strand in education, can help students develop higher-level competencies such as inquiry, collaboration, knowledge creation, agency and metacognition. Productive collaborative inquiry requires participants to collectively take cognitive responsibility (Zhang, Scardamalia, Reeve, \& Messina, 2009). However, facilitating students to collectively and sustainably take this responsibility and thus advance collective ideas instead of solely completing tasks is challenging. Collective cognitive responsibility includes the three dimensions of awareness of contributions, complementary contributions, and distributed engagement (Zhang et al., 2009).

Knowledge building is a collaborative-inquiry model, and considers the process of knowledge creation to be a social process (Scardamalia \& Bereiter, 2006). It refers to "collective cognitive responsibility for idea improvement" (Scardamalia \& Bereiter, 2006). In most knowledge-building implementations, the Knowledge Forum is used to promote and sustain the knowledge-building discourse. Research has suggested that students tend to sharing rather than create knowledge, which can be due to low-level collective cognitive knowledge resulting from a lack of an appropriate knowledge-building environment.

By recognizing the challenges and the requirements, a knowledge-building environment to help students take collective cognitive responsibility was designed in this study. The study aims to examine whether undergraduates were capable of taking collective responsibility to improve their knowledge-building discourse. This study is part of a larger project that focused on developing students higher-order competencies through knowledge-building environment augmented by learning analytics. The study aimed to answer the following two research questions.

(1) What are the characteristics of undergraduates' collective cognitive responsibility in the knowledge-building process?

(2) To what extent do undergraduates gradually take collective cognitive responsibility to advance community knowledge? 


\section{METHODS}

\subsection{Research Context and Participants}

The participants were 30 undergraduates from 24 disciplines in a key university that focused on preparing primary and secondary school teachers. They participated in the study for 4 months while taking a core course of literal education for 1.5 hours each week. The course is aimed at helping undergraduates deploy and develop skills in the process of inquiry and creating knowledge. Most students had low levels of motivation and limited skills of collaboration and inquiry in the initial stage, and they took this course to gain academic points for graduation. The course teacher had one year of teaching experience, had received her doctoral degree in information technology studies, and had expertise in knowledge-building pedagogy.

\subsection{Pedagogical Design}

The teacher used a three-phase knowledge-building model to help undergraduates familiarize themselves with knowledge building and to gradually take collective cognitive responsibility for idea improvement. The phases were to develop an awareness of their contributions and their skills of inquiry and collaboration through small-group design activities (e.g., making bridges using newspapers and posters) (Phase 1); to provide complementary contributions through question-oriented, idea-centered inquiry discourse on the Knowledge Forum (Phase 2); and to promote collective responsibility through reflecting on data indicating their participation, collaboration, and contributions (Phase 3).

\section{DATA ANALYSIS AND RESULTS}

Knowledge Forum writing was the primary data source. Our argument was that if students gradually assumed a higher level of collective responsibility they could generate productive Knowledge Forum discourse. The online discourse was pre-processed based on thematic analysis and then organized into inquiry threads. An inquiry thread is a sequence of notes that aim to address one principal problem (Zhang, Scardamalia, Lamon, Messina, \& Reeve, 2007). The goal of analyzing the inquiry threads was to obtain a holistic understanding of the students' ideas and provide a context for the subsequent analysis of the characteristics of cognitive collective responsibility. In total, 38 inquiry threads including 612 notes were developed.

Next, we conducted content analysis to analyze and characterize undergraduates' collective responsibility using the inquiry thread as the unit of analysis. We used the coding framework that was adapted from our previous research (Yang, van Aalst, Chan, \& Tian, 2016) to code the notes in each inquiry thread. Two raters independently coded the notes from three inquiry threads in the experimental class $(\mathrm{n}=190,30 \%)$. The inter-rater reliability was .78 for awareness of contributions, .79 for complementary contributions, and .78 for the wide-ranging complexity of questions and ideas (Cohen's kappas).

\subsection{Characterization of Collective Cognitive Responsibility}

We selected 14 large inquiry threads for content analysis, which were defined as threads that included more than 15 notes. The coding results are given in Table 1 .

Awareness of contribution and complementary contributions. Table 1 shows that students contributed a considerable number of notes to create shared understanding (70) and to negotiating a fit (119). The results suggest that undergraduate became aware of the emergent issues and others' ideas by reading notes on shared understanding and further negotiating a fit, and therefore were aware of peers' contributions. Table 1 also shows that students made complementary contributions through participating in problem-centered discourse (62 notes), regulating their inquiry (22), and synthesizing community ideas to attain a higher level (38).

Distributed engagement. To reveal students' distributed engagement, we used the Knowledge Building Discourse Explorer (KBDex, Oshima, Oshima, \& Matsuzawa, 2012), a socio-semantic network analysis tool. KBDex was developed to analyze knowledge-building discourse, and can support metrics of the three networks of degree centrality, betweeness centrality, and closeness centrality. Thus it can facilitate a visual 
inspection of the semantic relationships, an analysis of pivotal points and phases, and trend analysis. We selected 10 keywords that were highly relevant to students' inquiry topics from their online discourse for analysis. We argue that the keywords can represent the discourse content, so the closeness of keyword links and the number of keyword instances represent the density and diversity of discourse content, respectively.

Table 1. Number of Different Categories of Contributions and Epidemic Complexity in Inquiry Threads

\begin{tabular}{|c|c|c|c|c|c|c|}
\hline & & \multicolumn{2}{|c|}{ Awareness of contributions } & \multicolumn{3}{|c|}{ Complementary contributions } \\
\hline & & $\begin{array}{l}\text { Creating shared } \\
\text { understanding } \\
\text { (medium) }\end{array}$ & $\begin{array}{c}\text { Negotiating a fit } \\
\text { (high) }\end{array}$ & $\begin{array}{c}\text { Problem- } \\
\text { centered idea } \\
\text { uptake } \\
\text { (medium) }\end{array}$ & $\begin{array}{l}\text { Regulating } \\
\text { inquiry } \\
\text { (medium) }\end{array}$ & $\begin{array}{l}\text { Synthesizing notes } \\
\text { (high) }\end{array}$ \\
\hline Total & 318 & 70 & 119 & 62 & 22 & 38 \\
\hline Mean & 22.71 & 5 & 8.5 & 4.23 & 1.57 & 2.71 \\
\hline $\mathrm{SD}$ & 6.59 & 2.48 & 2.56 & 2.65 & 1.55 & 1.81 \\
\hline $1 \#$ & 20 & 7 & 4 & 3 & 3 & 1 \\
\hline 2\# & 18 & 3 & 8 & 5 & 2 & 0 \\
\hline $3 \#$ & 37 & 10 & 10 & 12 & 1 & 3 \\
\hline $4 \#$ & 35 & 6 & 14 & 7 & 3 & 5 \\
\hline $5 \#$ & 20 & 7 & 6 & 4 & 0 & 1 \\
\hline $6 \#$ & 21 & 4 & 12 & 2 & 0 & 3 \\
\hline $7 \#$ & 20 & 3 & 8 & 3 & 4 & 2 \\
\hline $8 \#$ & 16 & 3 & 8 & 2 & 1 & 2 \\
\hline 9\# & 29 & 7 & 8 & 6 & 0 & 7 \\
\hline $10 \#$ & 23 & 6 & 8 & 4 & 0 & 4 \\
\hline $11 \#$ & 23 & 7 & 8 & 4 & 0 & 4 \\
\hline $12 \#$ & 16 & 1 & 8 & 2 & 3 & 2 \\
\hline $13 \#$ & 23 & 3 & 11 & 3 & 4 & 2 \\
\hline $14 \#$ & 17 & 3 & 6 & 5 & 1 & 2 \\
\hline
\end{tabular}

Figure 1. Snapshots of the Network of Students Over Time

\subsection{Changes of Collective Cognitive Responsibility and Idea Improvement}

To measure the extent of changes in collective cognitive responsibility and idea improvement, we first sequenced the notes in each of the 14 large inquiry threads, based on the time of the last modification, and then divided the notes into two phases, each with an approximately equivalent number of notes. Table 2 shows that the frequency distributions for Phases 1 and 2 differed greatly. Generally, undergraduates in Phase 2 engaged in more high-level discourse moves than those in Phase 1. For example, they engaged more in synthesizing notes that were critical for knowledge creation in Phase 2 than in Phase 1.

Table 2 also shows that students in Phase 2 engaged more in discourse with higher explanatory power and quality, and in inquiry- and explanation-oriented discourse. For example, they produced many more "rise-above" notes than those in Phase 1. These results indicate that the undergraduates gradually advanced their community ideas. 


\section{CONCLUSIONS}

In this study we investigated whether undergraduates were capable of take collective cognitive responsibility in the knowledge-building process. We found that they were able to progressively take collective responsibility to develop a knowledge-building discourse. However, a deliberate design that encourages their development is required to achieve these outcomes. The design of the knowledge-building environment involved three components: (1) the creation of an error-free collaborative environment; (2) periodic tasks to promote the development of collective cognitive development; and (3) knowledge-building talks to prompt collaborative reflection and the thoughtful use of the assessment data. This study demonstrates the potential of a knowledge-building environment that engages undergraduates in an examination-centered culture. The study had implications for teachers and researchers who aim to design technology-supported learning environments that can engage students who are generally unmotivated and disengaged.

Table 2. Changes of Collective Responsibility and Community Ideas over Time

\begin{tabular}{|c|c|c|c|c|c|}
\hline \multirow{3}{*}{ Total notes } & & \multicolumn{2}{|c|}{ Phase 1} & \multicolumn{2}{|c|}{ Phase 2} \\
\hline & & \multicolumn{2}{|c|}{162} & \multicolumn{2}{|c|}{156} \\
\hline & & $\mathrm{f}$ & $\%$ & $\mathrm{~F}$ & $\%$ \\
\hline \multirow[t]{2}{*}{$\begin{array}{l}\text { Awareness of } \\
\text { contributions }\end{array}$} & $\begin{array}{l}\text { Creating shared } \\
\text { understanding (medium) }\end{array}$ & 50 & 30.86 & 20 & 12.18 \\
\hline & Negotiating a fit (high) & 52 & 32.10 & 67 & 42.95 \\
\hline \multirow[t]{3}{*}{$\begin{array}{l}\text { Complementary } \\
\text { contributions }\end{array}$} & $\begin{array}{l}\text { Problem-centered idea } \\
\text { uptake (high) }\end{array}$ & 30 & 18.52 & 30 & 19.23 \\
\hline & Regulating inquiry (high) & 13 & 8.02 & 9 & 5.77 \\
\hline & Synthesizing notes (high) & 14 & 8.64 & 29 & 18.47 \\
\hline \multirow{6}{*}{$\begin{array}{l}\text { Quality of } \\
\text { questions and } \\
\text { ideas }\end{array}$} & Fact-seeking & 3 & 1.85 & 0 & 0 \\
\hline & Explanation-seeking & 13 & 8.03 & 7 & 4.32 \\
\hline & Simple claim & 9 & 5.56 & 5 & 3.18 \\
\hline & Elaboration & 49 & 30.25 & 36 & 23.08 \\
\hline & Explanation & 72 & 44.44 & 77 & 49.36 \\
\hline & Rise-above & 16 & 9.88 & 32 & 20.51 \\
\hline
\end{tabular}

\section{ACKNOWLEDGEMENT}

This research was partly and financially supported by self-determined research funds of CCNU from the colleges' basic research and operation of MOE, and a grant from Ministry of Education of the People's Republic of China (Grant No. 18YJC880107).

\section{REFERENCES}

Chan, C. K. K., \& van Aalst, J. (2008). Collaborative inquiry and knowledge building in networked multimedia environments. In J. Voogt \& G. Knezek (Eds.), International handbook of information technology in primary and secondary education (pp. 299-316). Dordrecht, the Netherlands: Springer.

Oshima, J., et al, 2012. Knowledge Building Discourse Explorer: a social network analysis application for knowledge building discourse. Educational Technology Research and Development, Vol. 60, No. 5, pp 903-921.

Scardamalia, M., \& Bereiter, C. (2006). Knowledge building: Theory, pedagogy, and technology. In R. K. Sawyer (Ed.), The Cambridge handbook of the learning sciences (pp. 97-115). New York, NY: Cambridge University Press.

Yang, Y., et al, 2016. Reflective assessment in knowledge building by students with low academic achievement. International Journal of Computer-Supported Collaborative Learning, Vol. 11, No. 3, PP 281-311.

Zhang, J., Scardamalia, M., Lamon, M., Messina, R., \& Reeve, R. (2007). Socio-cognitive dynamics of knowledge building in the work of 9- and 10-year-olds. Educational Technology Research and Development, 55, 117-145.

Zhang, J., Scardamalia, M., Reeve, R., \& Messina, R. (2009). Designs for collective cognitive responsibility in knowledge-building communities. Journal of the Learning Sciences, 18, 7-44. doi: doi:10.1080/10508400802581676 